2019-03

The Effect of Exogenous Applications of Salicylic Acid on Drought Tolerance and Up-Regulation of the Drought Response Regulon of Iraqi Wheat

Kareem, F

http://hdl.handle.net/10026.1/16356

10.1007/s12892-017-0180-0

Journal of Crop Science and Biotechnology

Springer Science and Business Media LLC

All content in PEARL is protected by copyright law. Author manuscripts are made available in accordance with publisher policies. Please cite only the published version using the details provided on the item record or document. In the absence of an open licence (e.g. Creative Commons), permissions for further reuse of content should be sought from the publisher or author. 


\title{
The Effect of Exogenous Applications of Salicylic Acid and Molybdenum on the Tolerance of Drought in Wheat
}

\author{
Fakhriya Kareem, Hail Rihan and Michael P Fuller* \\ School of Biological and Marine Sciences, Plymouth University, UK
}

Submission: August 01, 2017; Published: August 11, 2017

"Corresponding author: Michael P Fuller, School of Biological and Marine Sciences, Plymouth University, Plymouth, UK, Tel: 004407513724273; Email: hail.rihan@plymouth.ac.uk

\begin{abstract}
This study investigated the effect of drought on the growth and yield components of two Iraqi wheat varieties (Tamooz 2 and Adana 99) and the effect of different concentrations of salicylic acid and molybdenum. Drought significantly decreased the growth rate and had a negative impact on the yield components in both varieties and it was confirmed that the yield and growth of Tamooz 2 variety was significantly better than Adana 99. It was demonstrated that salicylic acid and molybdenum improved the performance of both varieties of Iraqi wheat under both wellwatered and drought conditions. However, salicylic acid had a better general effect than molybdenum, although the difference was not significant in some of the studied parameters. The application of salicylic acid at a relatively low concentration was shown to have the most positive impact on the physiological, yield and growth parameters. We believe that the current study could have an important practical application in the field of cereal production
\end{abstract}

Keywords: Wheat; Salicylic acid; Molybdenum; Drought tolerance; Abiotic stress

\section{Introduction}

The first evidence that Salicylic Acid (SA) might be involved in plant defence systems was provided by White [1], who found that injection of Aspirin or SA into tobacco leaves enhanced resistance to subsequent infection by Tobacco Mosaic Virus (TMV). SA is a naturally occurring derivative of the group of phenolic acid compounds that are distributed in many species of monocotyledonous and dicotyledonous plants, including rice, barley, crabgrass and soybean. The amount of SA in the leaves and reproductive organs of angiosperm plants has been found to be approximately $1 \mu \mathrm{g}$ g- 1 fresh weight. The highest concentration of SA was detected in pathogen-infected necrotizing inflorescences. In addition, it is known that SA has a regulatory role in a range of physiological processes, such as photosynthesis, transpiration, nutrient uptake, chlorophyll synthesis and plant development [2]. SA was later recognized as an important signalling molecule that potentially influences plant tolerance to water stress because of its influence on the regulation of metabolic and physiological activities during the entire lifespan of the plant, affecting its growth parameters and bio-productivity [3].

These responses are directly activated by changing the water status of plant tissues, while others are triggered by signalling molecule transduction, which regulates growth and development and leads to a cascade of processes responsible for the physiological adaptation of the plant to stress conditions [4]. Besides this function of growth promotion, it has been reported in the literature during the last decade that exogenous application of SA to plants can play a role in enhancing wheat plant tolerance to some abiotic stresses, such as salinity Shakirova et al. [5] and drought stress [6-8]. Several studies support the stimulatory effect of SA on a number of morphological and physiological processes of plants, including growth, photosynthesis and other metabolic processes. This demonstrates a function as a protective agent in plants, modulating the plant response to various biotic and abiotic stresses, such as drought, cold, heat and osmotic stress [9]. Exogenous treatment of drought stressed plants with different levels $(0.5$ and $1.0 \mathrm{~mm})$ of SA not only caused a decline in the adverse effect of drought in yellow Maize (Zeamays L.) plants, but also stimulated physiological traits, productivity and plant resistance to drought stress [10]. Moreover, Farooq et al. [11] demonstrated that treatment of rice leaves (Oryza sativa L.) with SA (100mg L-1) had a positive effect on photosynthesis and plant growth compared to other treatments of 50 and $150 \mathrm{mgL}-1$ and induced better resistance to drought stress than soaking the seeds in the same SA solutions. 
The first indication of the physiological role of Molybdenum (Mo) as an essential micronutrient for plants was demonstrated by Bortels [12], who reported that supplementation of the culture medium with traces of Mo greatly increased the fixation of nitrogen and growth by microorganisms. In the biological system, molybdenum, as molybdate, is the dependent form for more than 50 enzymes in all organisms because of its availability to the cells by combining with the active sites of enzymes to form the molybdenum co-factor. Five of these molybdo-enzymes have been found in higher plants to be involved in the metabolism processes of nitrogen, purine, sulphur and phytohormones and can act in transducer reduction systems, such as hydroxylation of carbon centres under more moderate conditions [13]. These Moenzymes are nitrate reductase (NR), Xanthine dehydrogenase (XDH), sulphite oxidase (SO) and aldehyde oxidase (AO) respectively, and each has a crucial role in diverse metabolic pathways. For these reasons, a shortage of the Mo element in the substrate leads to loss of these essential metabolic functions, and ultimately to the death of the plants $[14,15]$. As a result of some reports, Molybdenum has been defined as a major growth promoter, and it was hypothesized that exogenous application of Mo can also induce abiotic stress tolerance in food crops [16]. As a consequence, Mo is currently one of the most studied topics in abiotic stress response research into drought, cold and salt stress [17-20].

Although a number of reports to date have indicated the protective role of SA under environmental stress conditions, the amount of research conducted on the effect of exogenous applications of SA on physiological characteristics and yield of wheat under drought stress condition is limited. Therefore, this experiment was conducted to study the effect of exogenous applications of the "anti-stress" compounds, SA and Mo, on the drought tolerance capacity of two Iraqi wheat varieties compared to untreated plants.

\section{Materials and Methods}

Two Iraqi wheat (Triticumaestivum L.) varieties, Tamooz 2 and Adana 99, were chosen as a model system. Variety Tamooz 2 was chosen as drought stress resistant and Adana 99 as drought stress sensitive [21]. Sixtypots were used, each containing about $13 \mathrm{~kg}$ of air-dried loam-based soil. The pots were placed in pot saucers and then brought up to full saturation point. Four hundred seeds of the two varieties were placed on wet absorbent laboratory blue tissue paper in sandwich boxes, and the seeds were allowed to germinate at $25{ }^{\circ} \mathrm{C}$ in a growth chamber (Sanyo Gallenkamp PLC LE 3202, England) for approximately 72 hours. After 3 days, the germinated seeds were planted (mid November 2014 ) in the pots and the plants were grown under greenhouse conditions in Skarden Garden, Plymouth University UK, under a $12 \mathrm{~h}$ photoperiod maintained with sodium vapour supplementary lighting. The experimental arrangement was a completely randomized block design (CRBD) with five treatments: control (water spray), SA (1.44 and $2.88 \mathrm{mM})$ and Mo $(0.15$ and $0.30 \mathrm{mM})$. Three replications were used with each treatment.

Growth stage codes were used according to Zadoks et al. [22]. The plants were grown according to good commercial practice. One month after sowing, the plants were sprayed with fungicide to control powdery mildew, and spraying was repeated twice more, with an interval period of one month. At the four-leaf stage (GS14), SA (1.44 and $2.88 \mathrm{mM})$ and Mo $(0.15$ and $0.30 \mathrm{mM})$ were sprayed onto designated pots whilst control plants were sprayed with distilled water. Half of the plants were maintained under non-stressed conditions and maintained at $70-100 \%$ of field capacity (FC).The other half were drought stressed with pots maintained at $50-70 \%$ FC. Soil moisture was monitored using a Theta probe (Delta T Devices) following calibration and production of a standard curve for the soil type used.

The measurements of Leaf stomatal conductance and chlorophyll-fluorescence were taken in the middle of 10 young fully expanded flag leaves of the main stem (not tillers) for both non-droughted and drought stressed plants. The leaves were randomly selected in all treatments per pot for both varieties and measured at thirty-eight days after the commencement of the watering regimes, and shortly before ear emergence (GS51), during a sunny day using a portable Delta T Porometer AP4 (Delta-T devices, Cambridge, UK) so as to record stomatal aperture of leaves in terms of their conductivity to water vapour (gs-cm s-1) at a light intensity of $210 \mu \mathrm{mols}$ m- $2 \mathrm{~s}-1$ similar to the procedure.

\section{Measurements of yield components}

Once the wheat plants had begun to senesce and showed signs of yellowing, the irrigation was terminated to allow the pots to dry and the plants to ripen naturally. Two weeks after ending the watering, the plants were ripe for harvest. All the plants were pulled from the soil and the roots cut off and discarded. The harvested plants were collected in paper storage bags and transferred to the laboratory for measurement of the following parameters:

\section{A. Spikes}

B. Each pot was dealt with as one unit (i.e. the plants in a pot were pooled). Spikes were cut from the stems of plants, counted and kept in separate paper storage bags. Then spike samples were dried in the oven at $80 \mathrm{oC}$ for two days until constant weight and weighed (Sartorius balance, model I8400P NO 35039, UK.)

\section{Stems}

D. The number of stems was counted (stems/pot) (NB: not all stems bore a spike). Stems and leaves from plants for each pot were placed in aluminium foil dishes and dried in a drying oven (Gallen kamp Economy Incubator size two, model $\mathrm{IH}-150$, England) at $80{ }^{\circ} \mathrm{C}$ for 2 days to dry until constant 
weight Singh \& Usha [7] then weighed (Precisa balances, Swiss quality, model 400M NO 13909, Switzerland).

E. Grain

F. Total grain dry weight was determined by threshing the spikes so as to separate the grains from the chaff, and then the number of grains for each spike was counted. The grain from all spikes was then pooled and the weight recorded (Sartorius balance, model I8400P NO 35039 UK). From these measurements, the average 1000-grain dry weight per pot, the grain yield per pot and the average grains per spike were obtained [23].

\section{Statistical analysis}

Results are presented as means \pm standard error (SE). All data were analysed using the statistical software Minitab (version 17) and balanced analysis of variance (ANOVA). Significant differences between means were assessed by the least significant difference test (LSD) at the probability of $95 \%$.

\section{Results}

The drought treatment had significant negative effects on stomatal conductance, chlorophyll a fluorescence, number of stems, shoot dry weights, number of spikes, spikes dry weight and grain dry weights $(\mathrm{p} \leq 0.001)$ (Figure 1$)$.

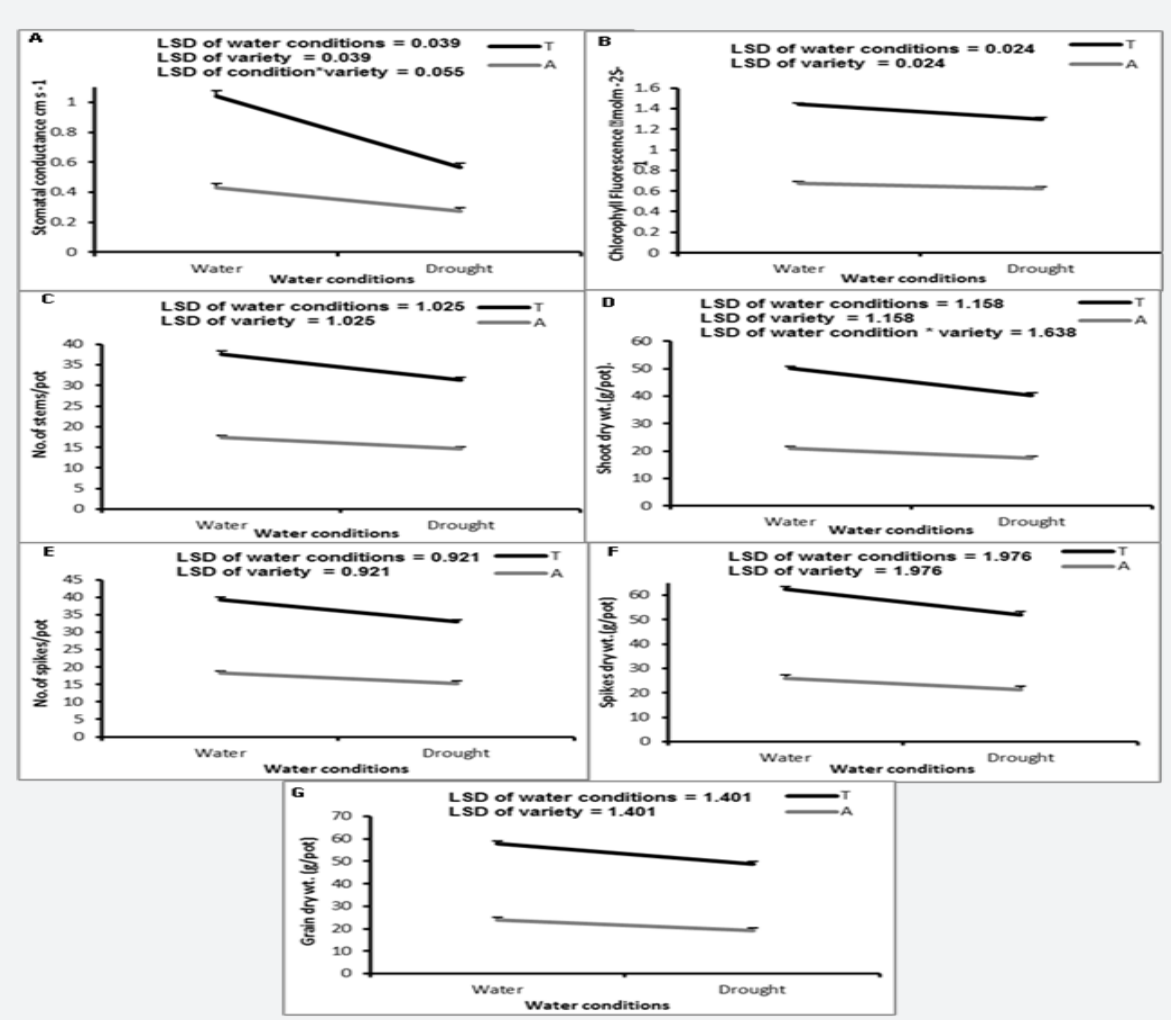

Figure 1: The effects of water condition and wheat variety on: A) stomatal conductance, B)chlorophyll a fluorescence, C) number of stems, D) shoot dry weight, E) number of spikes, F) spike dry weight, G)grain dry weight.

Leaf stomatal conductance, chlorophylla fluorescence, number of stems, shoot dry weight, number of spikes, spikes dry weight and grain dry weight were significantly higher in Tamooz 2 than in Adana 99 variety (Figure 1).

No significant effects of watering conditions or variety were observed on the average 1000 grain dry weight ( $p=0.92$ for the water condition and $\mathrm{p}=0.280$ for the variety).

Significant interaction between watering conditions and variety was observed on the leaf stomatal conductance $p \leq 0.001$ (Figure 1) and shoot dry weight $\mathrm{p} \leq 0.020$ (Figure 1)

\section{The effect of chemical treatments (SA and Mo) on leaf stomatal conductance}

The exogenous application of SA1 and SA2 significantly improved the leaf stomatal conductance compared to the control $(\mathrm{p} \leq 0.001)$. Spraying the pots with treatments of Mo1 and Mo2 also improved stomatal conductance slightly although this was not significantly different from the control. Treatment with the relatively low concentration of SA $(1.44 \mathrm{mM})$ stimulated the leaf stomatal conductance to a greater extent than the higher application rate (Figure 2). 


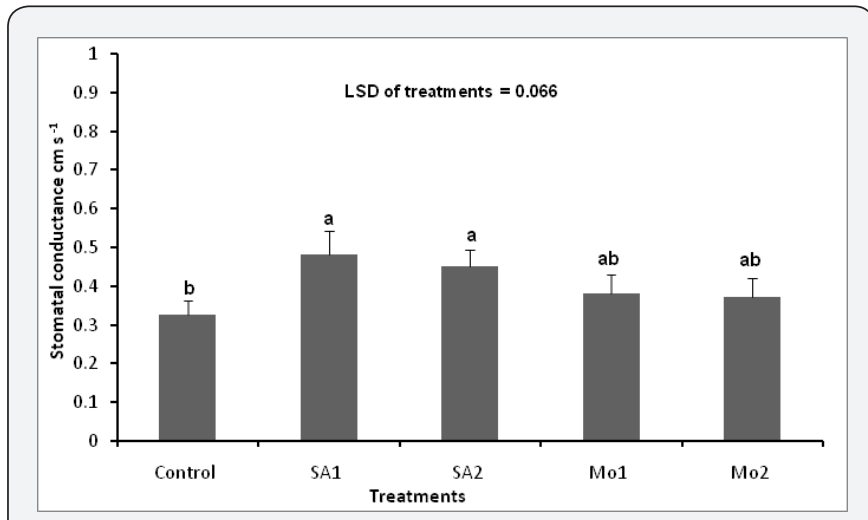

Figure 2: The effect of chemical treatments $\mathrm{SA}(\mathrm{SA} 1=1.44$ and $\mathrm{SA} 2=2.88 \mathrm{mM})$ and $\mathrm{Mo}(\mathrm{Mo} 1=0.15$ and $\mathrm{Mo} 2=0.30 \mathrm{mM})$ on leaf stomatal conductance of wheat.

There was no significant interaction between variety and chemical treatment in terms of the effect on leaf stomatal conductance $(p=0.270)$.

The effect of chemical treatments (SA and Mo) on leaf stomatal conductance under well watered and drought conditions

There was significant interaction between the watering conditions and chemical spray treatments $(p=0.044)$. The leaf stomatal conductance was significantly decreased by drought stress for all treatments. Under drought stress, SA1 significantly improved stomatal conductance compared to the control, but not to the same degree as under well-watered conditions (Figure 3).

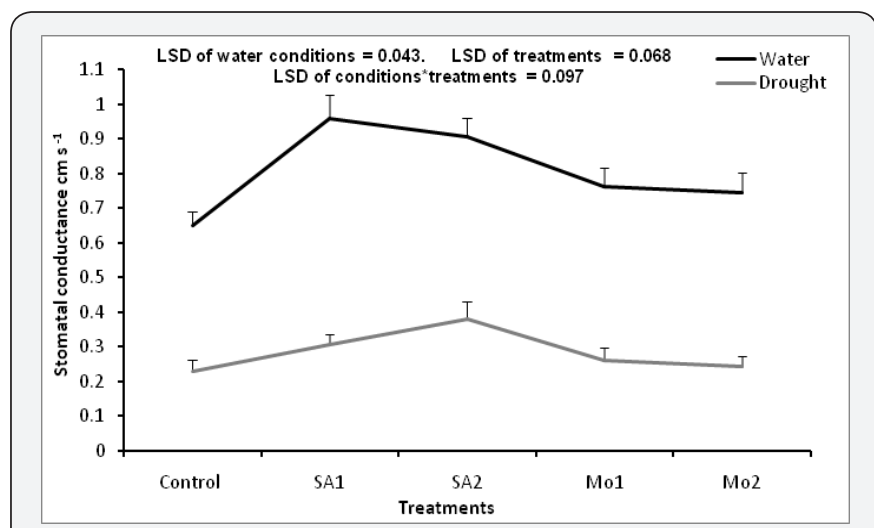

Figure 3: The effect of chemical treatments $(\mathrm{SA}(\mathrm{SA} 1=1.44$ and $\mathrm{SA} 2=2.88 \mathrm{mM})$ and $\mathrm{Mo}(\mathrm{Mo} 1=0.15$ and $\mathrm{Mo} 2=0.30$ $\mathrm{mM})$ ) on the leaf stomatal conductance of wheat varieties

The effect of chemical treatments (SA and Mo) on chlorophyll a fluorescence of wheat

The treatment of the plants with SA1 $(1.44 \mathrm{mM})$ had the greatest significant effect on chlorophyll a florescencep $\leq 0.001$ ) (Figure 4). Mo did not seem to have a significant effect on chlorophylla fluorescence (Figure 4).

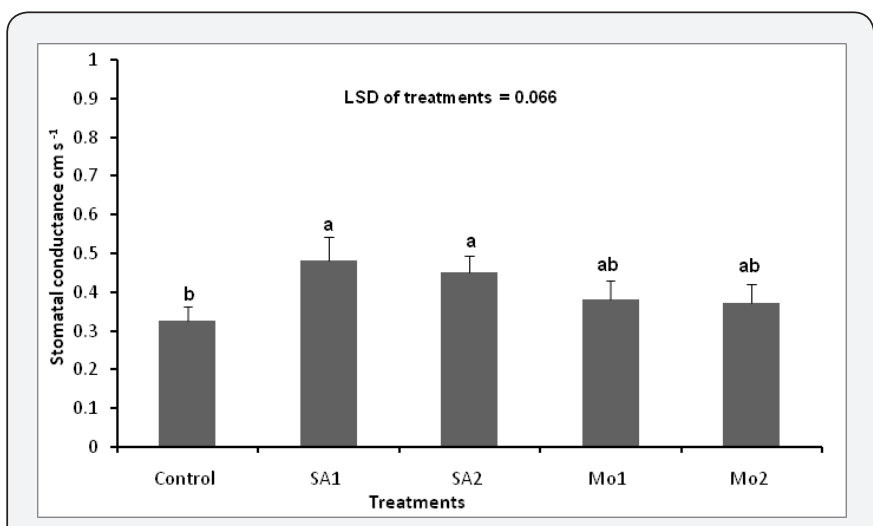

Figure 4: The effect of chemical treatments $\mathrm{SA}(\mathrm{SA} 1=1.44$ and SA2 $=2.88 \mathrm{mM})$ and $\mathrm{Mo}(\mathrm{Mo} 1=0.15$ and $\mathrm{Mo} 2=0.30 \mathrm{mM})$ on Chlorophyll Fluorescence $\mu \mathrm{molm}^{-2} \mathrm{~s}^{-1}$.

The effect of chemical treatments (SA and Mo) on number of stems per pot of wheat

The number of stems per pot was increased by all spray treatments of SA but this was only statistically significant for the SA1 treatment in comparison with other treatments. $(\mathrm{p} \leq 0.001)$ (Figure 5).

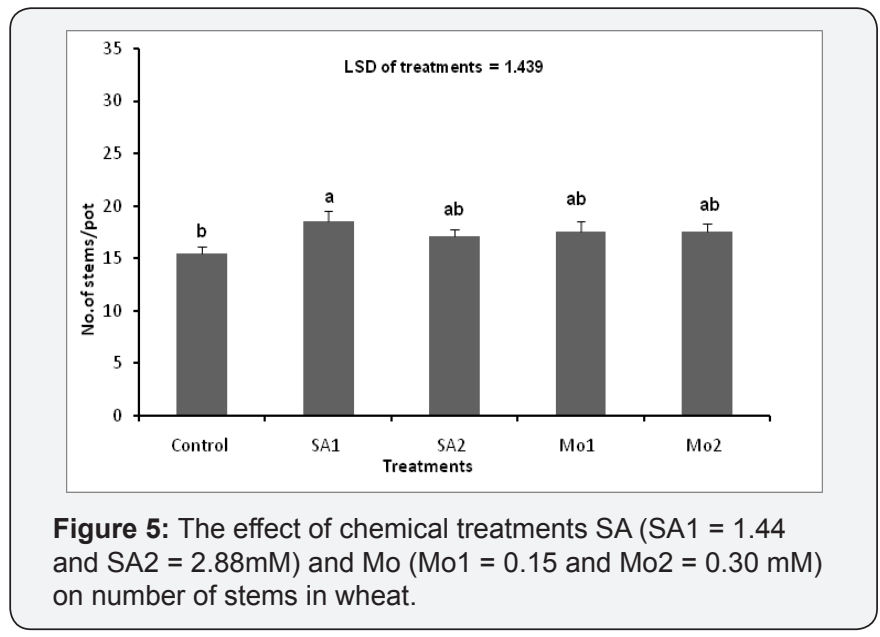

The effect of chemical treatments (SA and Mo) on shoot dry weight per pot

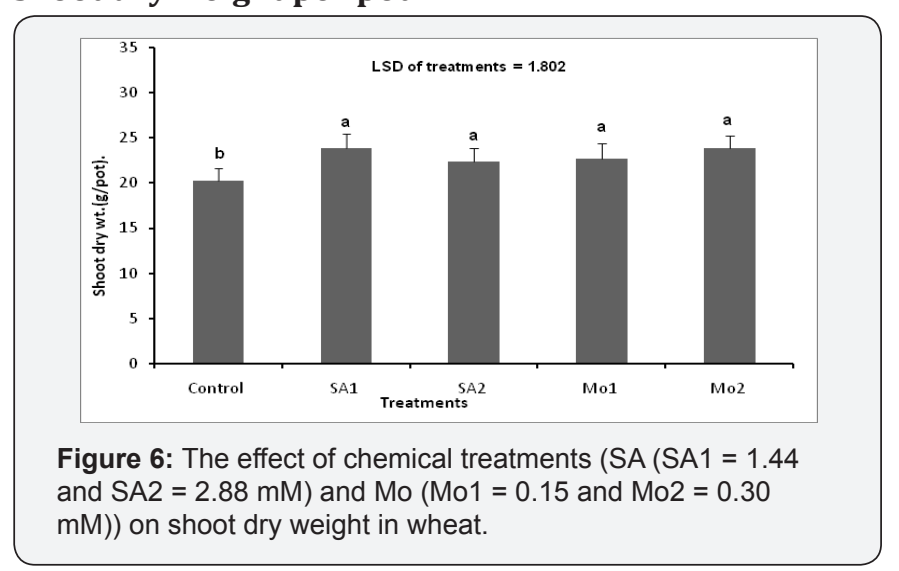


Both SA and Mo applications had a significant effect on the shoot dry weight $(p \leq 0.001)$ (Figure 6). The best results were obtained when plants were treated with SA1 (1.44mM) and Mo2 $(0.30 \mathrm{mM})$ (Figure 6).

\section{The effect of chemical treatments (SA and Mo) on number of spikes per pot}

The effect of the chemical treatments on the spike number/ pot was significant in comparison with the control $(\mathrm{p} \leq 0.001)$. Chemical treatments improved the number of spike per pot and the best treatment observed was SA1 (1.44mM) (Figure 7).

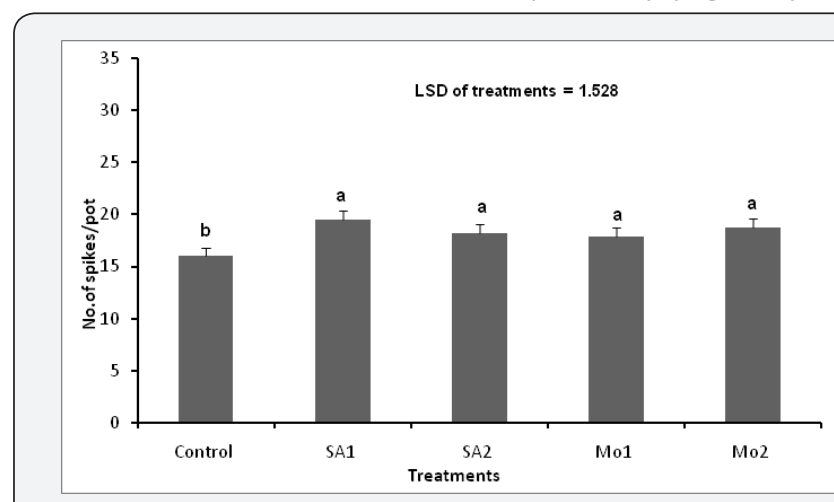

Figure 7: The effect of chemical treatments SA (SA1 $=1.44$ and $\mathrm{SA} 2=2.88 \mathrm{mM})$ and $\mathrm{Mo}(\mathrm{Mo} 1=0.15$ and $\mathrm{Mo} 2=0.30 \mathrm{mM})$ on number of spikes per pot of wheat.

The effect of chemical treatments (SA and Mo) on spike dry weight

Spraying the wheat plants with the chemical treatments SA1, SA2 and Mo2 had significant impact on the spike dry weight/ pot $(p \leq 0.001)$. A highly significant difference in the spikes dry weight/pot value was recorded for the plants treated with SA1 (1.44) mM compared to the non-sprayed control plants (Figure 8).

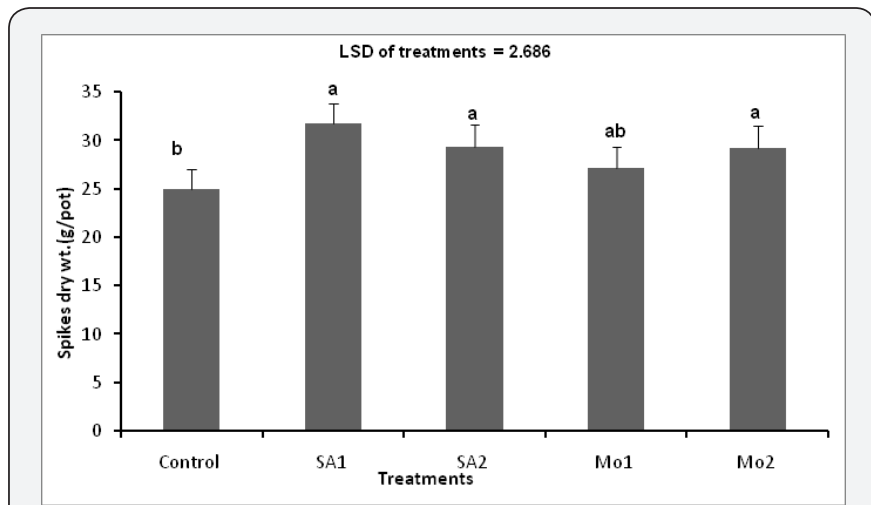

Figure 8: The effect of chemical treatments $\mathrm{SA}(\mathrm{SA} 1=1.44$ and SA2 $=2.88 \mathrm{mM})$ and $\mathrm{Mo}(\mathrm{Mo} 1=0.15$ and $\mathrm{Mo2}=0.30 \mathrm{mM})$ on spikes dry weight.

The effect of chemical treatments (SA and Mo) on grain dry weight

Chemical treatments had significant positive effects on grain dry weight compared to the control $(p=0.002)$. The SA1 treatment (lower concentration) improved the dry grain weight the most, with a $20 \%$ increase in grain dry weight per pot (Figure 9).

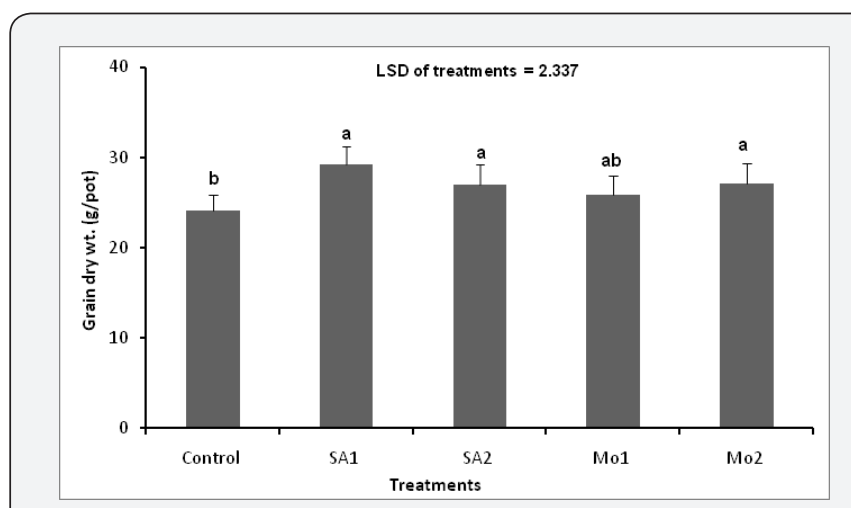

Figure 9: The effect of chemical treatments SA (SA1 $=1.44$ and $\mathrm{SA} 2=2.88 \mathrm{mM})$ and $\mathrm{Mo}(\mathrm{Mo} 1=0.15$ and $\mathrm{Mo2}=0.30 \mathrm{mM})$ on grain dry weight.

The effect of chemical treatments (SA and Mo) on average 1000 grain dry weight of wheat

Also, the chemical treatments spray had no significant effect on average 1000 grain dry weight values of wheat $(p=0.815)$ (Figures 10).

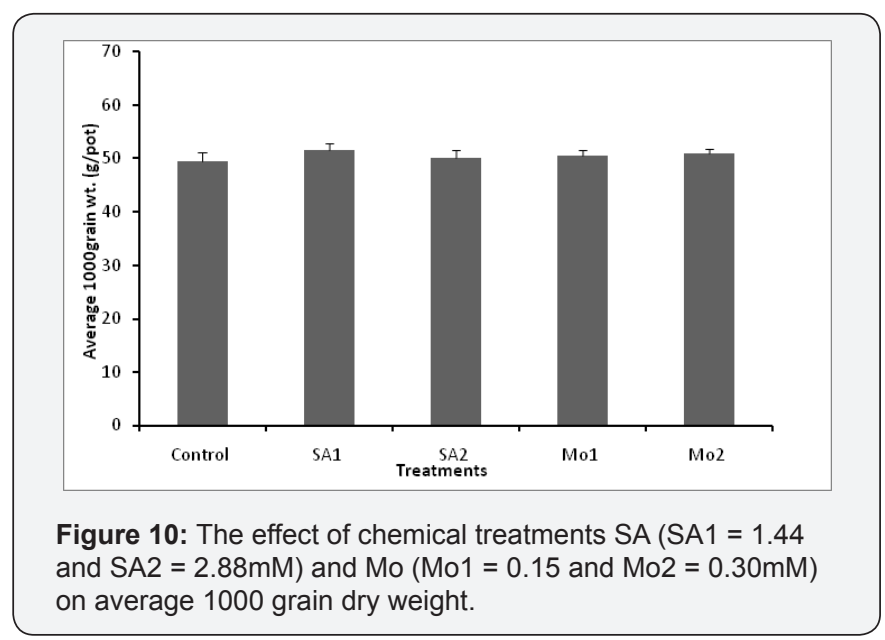

\section{Discussion}

The results of this study support those reported by Waseem et al. [8], where it was observed that exogenously applying 5 or $10 \mathrm{mgL}-1 \mathrm{SA}$ to the rooting medium had a significant effect on increasing leaf stomatal conductance and $\mathrm{CO} 2$ assimilation rate in wheat cultivars under non-stress conditions. Even though the cultivar S-24 showed a slight improvement in the conductance of stomata and cultivar MH-97 in the assimilation rate of $\mathrm{CO} 2$ under drought stress conditions with $5 \mathrm{mgL}-1 \mathrm{SA}$, application of salicylic acid did not mitigate the adverse effects caused by water deficit stress. Furthermore, it seems that these researchers supplied plants with SA through a rooting medium, in contrast to the present experiment, where a foliar application was applied which could explain the slight differences in the results obtained in both studies. In previous studies, similar responses 
were reported from the application of SA and its analogue, acetylsalicylic acid (ASA), to corn and soybean plants, where stomatal conductance and photosynthetic rates were effectively enhanced in all plants under greenhouse conditions [24]. Further, studies carried out on soybean plants (Glycine max L. Merrill) [25], and mustard plants (Brassica juncea) Fariduddin et al. [26], with foliar application of SA, enhanced the net photosynthetic rate, internal $\mathrm{CO} 2$ concentration, stomatal conductance and transpiration rate. The results of a study by Eraslan et al. [27] revealed that even though there were significant effects of SA on the increase of stomatal resistance in carrot plants (Daucus carota L. cv. Nantes) subjected to salinity stress compared to the control plants, the treatment (SA $0.5 \mathrm{mM}$ ) was not effective inalleviating salinity stress negative effects of $\mathrm{NaCl}$ and $\mathrm{Na} 2 \mathrm{SO} 4$ combined with Boron toxicity.

Several studies have demonstrated that SA, applied externally to plants, can induce plant tolerance to several abiotic stresses, including salt stress [5], drought stress in wheat [7], cold stress in maize Janda et al. [28] and Ultraviolet-B (UV-B) radiation stress in Kentucky bluegrass [29]. The inducible role of SA in plant tolerance against stresses may be due to its contributing to various physiological processes, such as a reduction in transpiration rate by stomatal closure and an enhancement of photosynthesis through the increase of intercellular CO2 concentration and nutrient uptake processes, for example, in spring wheat plants under salinity stress [30]. The efficiency of SA in these processes is determined by the influence of environmental factors, including water stress, in addition to physical factors to which the plants may have been exposed, such as light and/or temperature stress [31,32]. The effectiveness of SA in ameliorating the adverse effect of stress is not the same for all plants across all stress situations, but is dependent on internal factors, such as those related to the type of plant species and the physiological state of the plant. Regarding Mo effects on the tolerance characteristics of stress, a study by Sun et al. (2005) has shown that application of Mo to winter wheat plants under low temperature stress led to significant increases in the photosynthetic rate, and decreased stomatal conductance and water loss by transpiration.

The stem number/pot for variety Tamooz 2 under drought stress was decreased slightly more than in well-watered conditions in comparison to the variety Adana 99. This indicates that the Adana 99 variety is more drought-tolerant than Tamooz 2. Al-Temimi et al. [33] in their study of wheat varieties, noticed a significant reduction in the number of stems due to the influence of water stress. The results recorded here showed that the number of stems was greater in drought tolerant cultivar Tamooz 2 than in the non-tolerant cultivar Adana 99.

Drought stress decreased the dry mass of shoots for variety Tamooz 2 compared to Adana 99, indicating they responded differently to stress. The spray treatment with SA significantly increased the shoot dry weight. This is in agreement with Khan et al. (2003), who revealed that SA and the related compound ASA applied to corn and soybean plants caused significant increase of the plant dry mass. Waseem et al. (2006) also revealed that wheat cultivar MH-97 responded positively to supplying the rooting medium with SA $5 \mathrm{mgL}-1$ by an increase in the shoot dry mass under drought stress conditions. A significant stimulation of shoot size was observed when wheat seedlings were treated with a lower concentration of salicylic acid, thereby enhancing the shoot dry mass of plants treated with SA [34]. An enhanced growth of the shoot system resulted when plants of Tagetes erecta were treated with low concentrations of salicylic acid [35]. Moreover, in a pot experiment carried out by Hussein et al. [36], treatment of wheat plants with the rate of 200ppm SA improved growth characteristic of shoot dry weight when the plants were sprayed with salicylic acid and irrigated with tap water. A decrease in vegetative growth parameters was detected when salt concentrations in the irrigation water were increased. Farooq et al. [11] applied SA at concentration $100 \mathrm{mg} \mathrm{L-1} \mathrm{through}$ seed soaking and foliar spraying of rice plants (Oryza sativa L.) and indicated that it did not alleviate the negative effect of water deficit $(50 \% \mathrm{FC})$, nor affect the rate of photosynthesis and seedling dry weight as compared with plants under well-watered conditions. Our results are contrary to those reported by Singh \& Usha [7] who found that treatments of $2 \mathrm{mM}$ of SA did not affect wheat dry biomass of plants under a water sufficient regime. Inversely, dry weight of plants treated with SA was significantly improved under drought stress. Moreover, Idrees et al. [37] pointed out the positive effect of salicylic acid on the growth of shoots in varieties Neema and Krishna of lemongrass plants (Cymbopogon flexuosus Steud. Wats in ameliorating effects of water stress conditions of $75 \%$ and 50\% FC. Furthermore, foliar spray treatments of the plants with 10-5 M SA concentration showed significantly higher shoot dry weight compared to control.

Yu et al. [38] evaluated the influence of Mo application at the seedling stage on increasing shoot dry matter for most winter wheat cultivars; but to meet the Mo requirement for the whole growing period, foliar spraying of seeds with Mo was carried out in order to provide optimum growth during the plants' cycle. In a hydroponic study, it was shown that application of Mo treatment resulted in a significant increase in the average shoot dry weight at 12 days of exposure of cultivars of winter wheat plants Triticum aestivum to drought stress demonstrating the role of Mo in the adjustment of the osmotic system to protect wheat against stress [39].

It was also observed that the effect of SA may be attributed to its inducible effect on enzyme activity of photosynthetic processes, namely Rubisco and Phosphoenolpyruvate (PEP) carboxylase. Accordingly, SA-treated plants may be responsible 
for the improved dry matter in wheat seedlings under drought stress by maintaining the stability of membranes $[7,40]$.

Otherwise, the decrease in dry mass may be attributed to reduced protection due to the adverse effect of drought stress on water stressed plants treated with SA treatments.

According to the current results, a slightly greater effect of drought stress on yield characteristics was observed in wheat plant variety Tamooz 2, compared to variety Adana 99.The number of spikes/pot was significantly increased with the application of a low concentration of SA. In support of our findings, studies of Hayat et al. [41] and Klossig \& Malamy [42] revealed that SA application enhanced the activities of various physiological and biochemical characteristics, such as photosynthetic reactions, flowering and plant development, and may also result in inducing fruit yield and productivity in plants. Our results are also in agreement with evidence obtained on treating African violet plants, (Saintpaulia ionantha Wendl), with a low concentration of SA $0.1 \mathrm{mM}$. The treatment enhanced the number of flowers per plant and caused early flowering when grown under greenhouse conditions, in comparison with the control plants . Fariduddin et al. [26] reported an increase in the number of pods and the seed yield of mustard plant species (Brassica juncea Czern and Coss cv. Varuna).The results of our investigations contradict other research, which found that exogenous application of SA promotes crop production and counteracts the yield components inhibition caused by abiotic stresses, including drought stress in wheat plants Abdelkader et al. [43] and maize plants [44]. The determined effects of drought stress and genotype variation in drought tolerance could be related to the pre-treatment of the plants with $S A$, resulting in an accumulation of ABA, which might have contributed to providing pre-adaptation of seedlings under abiotic stress. Moreover, the exogenous applications of SA might affect flowering as a result of the interaction with other plant regulators e.g. gibberellins, affecting cell division rate in root apical meristem of plants by raising levels of IAA and cytokinins in stressed wheat plants and thereby increasing growth and productivity of plants $[45,46]$.

Wu et al. [39] showed that drought stress decreased spike numbers and grain yield of winter wheat (Triticum aestivum) whether or not Mo was applied. However, they demonstrated that Mo application significantly enhanced spike numbers and grain yield in wheat under drought conditions. Ghafarian et al. [18] also provided evidence of the effects of Mo effects on improving the performance of wheat plants. Spraying with a concentration of Mo of $1 \%$ increased the yield measurements, such as the number of spikes of water stressed plants compared to those of non-stressed plants, thereby providing tolerance against the damaging effects of drought stress. Total grain dry weight of variety plant variety Tamooz 2 was significantly better than Adana 99 under both well-watered and drought stress conditions, confirming that it are a higher yielding variety.

SA treatment improved the dry grain weight under both well-watered and drought conditions. Salicylic acid plays a regulatory role in the physiological process of fertilisation, which results in a significant increase in grain dry weight during flowering. Evidence by Grown (2012) showed that productivity of sunflower plants exposed to drought stress was significantly improved by SA treatment. Similarly, Azimi et al. [47] showed that the damaging effects of moisture stress were alleviated by exogenous application of SA in wheat seedlings and resulted in raising the values of grain dry weight/plant. It was further reported by Zamaninejad et al. [44] that the application of salicylic acid ( $1 \mathrm{mM}$ ) on maize plants (Zea mays L.) modified the negative effects of water stress on grain yield by increasing grain number/spikes significantly.

A decrease of grain yield under drought was lower in Motreated plants (applied by pre-treatment seed/foliar spray) than in untreated plants [38]. Likewise, other researchers have shown that Mo treatment enhances stress tolerance [17], where the effect of applying Mo through seed soaking/foliar spray was correlated to the tolerance of both spring and winter wheat genotypes to low temperature stress [17]. Additionally, a comprehensive study of Rihan et al. [48] verified that cold tolerance in cauliflower plants (Brassica oleracea var. botrytis) improved by utilising Mo in artificial seeds [49-51].

It appears that treatment of wheat plants with SA and Mo using only one mode of application with one spray is not sufficient for crop plants to complete their whole life cycle under conditions of limited water supply. It can be interpreted that the influence of SA on the improvement of the plants' tolerance to drought is affected by numerous factors, such as concentration, method of application, duration of treatment, species and also the physiological state of the plant.

\section{Conclusion}

It was demonstrated that the growth parameters and yield components in Tamooz 2 was significantly higher than those of Adana 99. Drought treatment resulted in significant reduction in growth and yields characteristics in wheat inboth Tamooz 2 and Adana 99 varieties. Both Mo and SA had a significant impact on the growth and yield component of wheat under both wellwatered and drought conditions. However, SA seems to have a greater impact on the growth and yield of wheat compared to MO, and the most positive effect was observed when SA was applied at a relatively low concentration. The results reported in this study could have an application for wheat growers in dry areas. 


\section{Acknowledgment}

Authors would like to thanks the Ministry of Higher Education and Scientific Research, Kurdistan Regional Government/ Iraq for providing a PhD grant to Fakhriya Kareem.

\section{References}

1. White R (1979) Acetylsalicylic acid (aspirin) induces resistance to tobacco mosaic virus in tobacco. Virology 99(2): 410-412.

2. Raskin I (1992) Role of Salicylic acid in plants. Annual Review of Plant Biology 43: 439-463.

3. Popova L, Pancheva T, Uzunova A (1997) Salicylic acid: properties, biosynthesis and physiological role. Bulgarian Journal Plant Physiology 23: 85-93.

4. Reddy AR, Chaitanya KV, Vivekanandan M (2004) Drought-induced responses of photosynthesis and antioxidant metabolism in higher plants. Journal of Plant Physiology 161(11): 1189-1202.

5. Shakirova FM, Sakhabutdinova AR, Bezrukova MV, Fatkhutdinova RA, Fatkhutdinova DR (2003) Changes in the hormonal status of wheat seedlings induced by salicylic acid and salinity. Plant Science 164: 317322.

6. Amin A, Rashad E-SM, Gharib F (2008) Changes in morphological, physiological and reproductive characters of wheat plants as affected by foliar application with salicylic acid and ascorbic acid. Australian Journal Basic and Applied Science 2(2): 252-261.

7. Singh B, Usha K (2003) Salicylic acid induced physiological and biochemical changes in wheat seedlings under water stress. Plant Growth Regulation 39(2): 137-141.

8. Waseem M, Athar H, Ashraf M (2006) Effect of salicylic acid applied through rooting medium on drought tolerance of wheat. Pakistan Journal of Botany.

9. Hayat Q Hayat S, Irfan M, Ahmad A (2010) Effect of exogenous salicylic acid under changing environment: a review. Environmental and Experimental Botany 68: 14-25.

10. Elgamaal AA, Maswada HF (2013) Response of three yellow maize hybrids to exogenous salicylic acid under two irrigation intervals. Asian Journal of Crop Science 5(3): 264-274.

11. Farooq M, Basra S, Wahid A, Ahmad N, Saleem B (2009) Improving the drought tolerance in rice (Oryza sativa L.) by exogenous application of salicylic acid. Journal of Agronomy and Crop Science 195(4): 237-246.

12. Bortels $H$ (1930) Molybdenum as a catalyst in the biological fixation of nitrogen. Arch Microbial 1: 333-342.

13. Mendel RR (2013) The molybdenum cofactor. Journal of Biological Chemistry 288(19): 13165-13172.

14. Koshiba T, Saito E, Ono N, Yamamoto N, Sato M (1996) Purification and properties of flavin and molybdenum containing aldehyde oxidase from coleoptiles of maize. Plant Physiol 110(3): 781-789.

15. Walker-Simmons M, Kudrna DA, Warner RL (1989) Reduced accumulation of ABA during water stress in a molybdenum cofactor mutant of barley. Plant Physiology 90(2): 728-733.

16. Taiz L, Zeiger E (2004) Fisiologia do estresse Fisiologia Vegetal 4: 738772 .

17. Al-Issawi M, Rihan HZ, Woldie WA, Burchett S, Fuller MP (2013) Exogenous application of molybdenum affects the expression of CBF14 and the development of frost tolerance in wheat. Plant Physiol Biochem 63: 77-81.

18. Ghafarian AH, Zarghami R, Zand B, Bayat V (2013) Wheat performance as affected by foliar application of molybdenum (Mo) under drought stress condition. International Journal of Agronomy and Plant Production 4(11): 3050-3056.

19. Sun X, Hu C, Tan Q Liu J, Liu H (2009) Effects of molybdenum on expression of cold-responsive genes in abscisic acid (ABA)-dependent and $A B A-i n d e p e n d e n t$ pathways in winter wheat under lowtemperature stress. Ann Bot 104(2): 345-356.

20.Zhang M (2012) Molybdenum improves antioxidant and osmoticadjustment ability against salt stress in Chinese cabbage (Brassica campestris L. ssp. Pekinensis). Plant and Soil 355(1-2): 375-383.

21. Kareem F (2017) The influence of exogenously applied "anti-stress" agents in the upregulation of the drought response in Iraqi wheat varieties. Plymouth University, UK.

22. Zadoks JC, Chang TT, Konzak CF (1974) A decimal code for the growth stages of cereals. Weed Research 14: 415-421.

23. Forno DA (1972) Laboratory manual for physiological studies of rice. Int Rice Res Inst pp. 61.

24. Khan W, Prithiviraj B, Smith DL (2003) Photosynthetic responses of corn and soybean to foliar application of salicylates. J Plant Physiol 160(5): 485-492.

25. Kumar P, Lakshmi N, Mani V (2000) Interactive effects of salicylic acid and phytohormones on photosynthesis and grain yield of soybean (Glycine max L. Merrill). Physiology and Molecular Biology of Plants 6: $179-186$

26. Fariduddin Q, Hayat S, Ahmad A (2003) Salicylic acid influences net photosynthetic rate, carboxylation efficiency, nitrate reductase activity, and seed yield in Brassica juncea. Photosynthetica 41 (2): 281-284.

27. Eraslan F, Inal A, Gunes A, Alpaslan M (2007) Impact of exogenous salicylic acid on the growth, antioxidant activity and physiology of carrot plants subjected to combined salinity and boron toxicity. Scientia Horticulturae 113: 120-128.

28. Janda T, Szalai G, Tari I, Paldi E (1999) Hydroponic treatment with salicylic acid decreases the effects of chilling injury in maize (Zea mays L.) plants. Planta 208(2): 175-180.

29. Ervin EH, Zhang X, Fike JH (2004) Ultraviolet-B radiation damage on Kentucky Bluegrass II: Hormone supplement effects. Hort Science 39(6): 1471-1474.

30. Arfan M, Athar HR, Ashraf M (2007) Does exogenous application of salicylic acid through the rooting medium modulate growth and photosynthetic capacity in two differently adapted spring wheat cultivars under salt stress? J Plant Physiol164(6): 685-694.

31. Janda T, Horvath E, Szalai G, Paldi E (2007) Role of salicylic acid in the induction of abiotic stress tolerance. In: Hayat S, Ahmad A (Eds.), Salicylic acid: A plant hormone. Springer, Netherlands, pp. 91-150.

32. Patel M, Golakiya B (1988) Effect of water stress on yield attributes and yield of groundnut (Arachis hypogaea) vol 58. Indian Counc Agricultural Res Icar Bhawan Pusa, New Delhi 110 012, India.

33. Al-Temimi HN, Al-Shahwany AW, Alsaadawi IS (2013) Screening of bread wheat cultivars (Triticum aestivum L.) to water deficit stress under field conditions Iraqi. Journal of Science 54(3): 577-584.

34. Shakirova F (2007) Role of hormonal system in the manifestation of growth promoting and anti stress action of salicylic acid. In: Hayat S, Ahmad A (Eds.), Salicylic acid: a plant hormone. Springer, Netherlands, pp. 69-89.

35. Sandoval Yepiz MdR (2004) Reguladores de crecimiento XXIII: Efecto del ácido salićlico en la biomasa del Cempazuchitl (Tagetes erecta L.).

36. Hussein M, Balbaa L, Gaballah M (2007) Salicylic acid and salinity effects on growth of maize plants. Research Journal of Agriculture and Biological Sciences 3(4): 321-328. 
37. Idrees M, Khan MMA, Aftab T, Naeem M, Hashmi N (2010) Salicylic acid-induced physiological and biochemical changes in lemongrass varieties under water stress. Journal of Plant Interactions 5(4): 293 303.

38. Yu M, Hu C, Wang Y (1999) Influences of seed molybdenum and molybdenum application on nitrate reductase activity, shoot dry matter, and grain yields of winter wheat cultivars. Journal of plant nutrition 22(9): 1433-1441.

39. Wu S, Hu C, Tan Q, Nie Z, Sun X (2014) Effects of molybdenum on water utilization, antioxidative defense system and osmotic-adjustment ability in winter wheat (Triticum aestivum) under drought stress. Plant Physiol Biochem 83: 365-374.

40. Rajasekaran L, Blake T (1999) New plant growth regulators protect photosynthesis and enhance growth under drought of jack pine seedlings. Journal of Plant Growth Regulation 18(4): 175-181.

41. Hayat S, Ali B, Ahmad A (2007) Salicylic acid: biosynthesis, metabolism and physiological role in plants. In: Hayat S, Ahmad A (Eds.), Salicylic acid: A plant hormone. Springer, Netherlands, pp. 1-14

42. Klessig DF, Malamy J (1994) The salicylic acid signal in plants. In: Palme K (Ed.), Signals and Signal Transduction Pathways in Plants. Springer, Netherlands, pp. 203-222.

43. Abdelkader AF, Hassanein RA, Ali H (2012) Studies on effects of salicylic acid and Thoreau on biochemical activities and yield production in wheat (Triticum aestivum var. Gimaza 9) plants grown under drought stress. African Journal of Biotechnology 11(64): 12728-12739.

44. Zamaninejad M, Khavari Khorasani S, Jami Moeini M, Heidarian AR
(2013) Effect of salicylic acid on morphological characteristics, yield and yield components of corn (Zea mays L.) under drought condition. Euro J Exp Bio 3(2): 153-161.

45. Lata C, Muthamilarasan M, Prasad M (2015) Drought stress responses and signal transduction in plants. In: Pandey G (Ed.), Elucidation of Abiotic Stress Signaling in Plants. Springer, USA, pp. 195-225.

46. Sakhabutdinova A, Fatkhutdinova D, Bezrukova M, Shakirova F (2003) Salicylic acid prevents the damaging action of stress factors on wheat plants. Bulgarian Journal Plant Physiol 21: 314-319.

47. Azimi MS, Daneshian J, Sayfzadeh S, Zare S (2013) Evaluation of amino acid and salicylic acid application on yield and growth of wheat under water deficit International. Intl J Agri Crop Sci 5(8): 816-819.

48. Rihan HZ, Al-Issawi M, Al Shamari M, Woldie WA, Kiernan M, et al. (2014) The effect of molybdenum on the molecular control of cold tolerance in cauliflower (Brassica oleracea var. botrytis) artificial seeds. Plant Cell Tissue and Organ Culture (PCTOC) 118(2): 215-228.

49. Grown B (2012) Physiological role of salicylic acid in improving performance, yield and some biochemical aspects of sunflower plant grown under newly reclaimed sandy soil. Australian Journal of Basic and Applied Sciences 6(4): 82-89.

50. Martin-Mex R, Villanueva-Couoh E, Herrera-Campos T, LarqueSaavedra A (2005) Positive effect of salicylates on the flowering of African violet. Scientia Horticulturae 103(4): 499-502.

51. Sun X, Hu C, Tan Q Gan Q (2005) Effects of molybdenum on photosynthetic characteristics in winter wheat under low temperature stress. Zuo wu xue bao 32(9): 1418-1422.

\section{Your next submission with Juniper Publishers will reach you the below assets}

- Quality Editorial service

- Swift Peer Review

- Reprints availability

- E-prints Service

- Manuscript Podcast for convenient understanding

- Global attainment for your research

- Manuscript accessibility in different formats

( Pdf, E-pub, Full Text, Audio)

- Unceasing customer service

Track the below URL for one-step submission https://juniperpublishers.com/online-submission.php 